\title{
Riesgos medioambientales en los espacios informativos: análisis cualitativo de la televisión española
}

\author{
Eva ESPINAR RUIZ \\ Universidad de Alicante \\ eva.espinar@ua.es \\ Anna SAMUELSSON \\ Universidad de Uppsala \\ anna.samuelsson@gender.uu.se
}

Recibido: 28 de noviembre de 2011

Aceptado: 8 de octubre de 2012

\section{Resumen}

Dada la influencia fundamental de los medios de comunicación en la difusión de amenazas y riesgos, nuestro objetivo es analizar el discurso mediático en torno a un riesgo en particular: el medioambiental. A partir de una muestra de 84 programas informativos emitidos en las tres cadenas de televisión españolas con mayores índices de audiencia a nivel nacional, se ha localizado y analizado un total de 138 noticias, todas ellas relativas al medio ambiente y la naturaleza. La información recogida ha sido codificada y clasificada de acuerdo a cuatro temáticas: causas, consecuencias, soluciones y referencias a problemas medioambientales. En términos generales, las noticias tienden a centrarse en eventos concretos y a mostrar preferencia por contenidos emocionales, de entretenimiento o anecdóticos, frente a explicaciones en torno a soluciones, consecuencias y, sobre todo, causas de los problemas medioambientales.

Palabras clave: Análisis cualitativo, televisión, riesgo medioambiental, noticias.

\section{Environmental Risks in the News: A Qualitative Analysis of Spanish Television News programs}

\begin{abstract}
Given the important role mass media play in the dissemination of risks, this article analysis the media discourse about a particular risk: the environmental one. From a sample of 84 news programs broadcast by the three Spanish television channels with the highest national ratings, we have analyzed a total of 138 pieces of news related to the environment and the nature. Applying qualitative methodology, the information has been classified looking for discourses around: references to environmental risks, causes, consequences and solutions. In general terms, news tend to focus on specific events and display their preference to emotional contents, entertainment or anecdotal facts, compared to the explanation of solutions, consequences and, above all, causes.
\end{abstract}

Keywords: Qualitative analysis, television, environmental risk, news.

Referencia normalizada: ESPINAR RUIZ, Eva y SAMULESSON, Anna (2012): "Riesgos medioambientales en los espacios informativos: análisis cualitativo de la televisión española". Estudios sobre el mensaje periodístico, vol. 18, núm. 2 (julio-diciembre), págs.: 703-719. Madrid, Servicio de Publicaciones de la Universidad Complutense.

Sumario: 1. Introducción. 2. Medios de comunicación y riesgo medioambiental. 3. Planteamiento metodológico. 4. Resultados; 4.1. Medidas, decisiones, declaraciones o actos; 4.2. Desastres medioambientales; 4.3. Consecuencias, causas y soluciones. 5. Conclusiones. 6. Referencias bibliográficas. 


\section{Introducción}

El estudio de los efectos de los medios de comunicación está repleto de desacuerdos o, tal y como afirma VilCHES (1993: 13), de "avances, retrocesos y dispersiones". Sin embargo, a pesar de las discrepancias, hoy día puede hablarse de un acuerdo generalizado en torno a la existencia de efectos importantes, especialmente de carácter cognitivo (McQuaIL, 2000: 497-501). De esta forma, en la medida en que los medios de comunicación son una de las principales fuentes de información sobre la realidad, ejercen una influencia fundamental en la comprensión que la audiencia tiene de tal realidad e, indirectamente, en su actitud hacia la misma (CURRAN, 2005: 168). En definitiva, podemos concluir, junto a TULLOCH y ZINN (2011:1), que "the experience of society and the interpretation of our everyday life are fundamentally mediated by the media".

Entre otras cuestiones, los medios de comunicación se han constituido en la principal fuente de información en materia de percepción de riesgos (MAJOR y ATWOOD, 2004: 295). Su influencia es clave a la hora de asociar riesgos con determinadas características y asignarles una mayor o menor importancia, tal y como se deduce de los trabajos realizados desde la agenda-setting (McComBs, 2005), las teorías del cultivo (GERBNER, 1998) y las teorías del encuadre o framing (HANSEN, 2011: 15); así como del análisis de la construcción de pánicos morales (CRITCHER, 2006) o de la amplificación social de riesgos (PIDGEON et al., 2003). Esta influencia resulta determinante en el caso de aquellos riesgos complejos, difícilmente perceptibles de forma directa y de efectos a largo plazo, como es el caso de los riesgos medioambientales (Howard-Williams, 2011: 28). Para este tipo de riesgos, el papel de los medios de comunicación como fuente fundamental de información toma especial relevancia (Cox, 2006).

Por ello, reconociendo el protagonismo de los medios a la hora de definir la importancia y características de los riesgos medioambientales, en este artículo se analiza la forma en que los medios españoles hablan de tales riesgos. En concreto, se ha considerado el medio que sigue siendo dominante, la televisión y, específicamente, los espacios informativos. Así, a partir de una muestra de telediarios de las tres cadenas de televisión con mayores índices de audiencia en el ámbito estatal, el objetivo es analizar el tratamiento que en ellos se da al riesgo medioambiental ${ }^{1}$. Este análisis resulta especialmente pertinente si tenemos en cuenta los resultados que arrojan los Eurobarómetros que han incorporado la temática medioambiental ${ }^{2}$. En ellos se observa que la mayor parte de los ciudadanos europeos y, en concreto, españoles (según datos de 2011, el $94 \%$ y el $95 \%$, respectivamente) califican como importante o muy importante la protección del medio ambiente. Sin embargo, el $46 \%$ de los españoles, frente al $60 \%$ de los europeos, se considera bien informado sobre temas medioambientales. Dadas estas diferencias, parece necesario analizar cómo están hablando de los riesgos

1 Los resultados derivan de un proyecto de investigación subvencionado por la Generalitat Valenciana (Referencia: GV/2007/146).

2 Información accesible en: http://ec.europa.eu/public_opinion/index_en.htm [fecha de consulta: el 17 de noviembre de 2011]. Los porcentajes que aquí se muestran proceden del Eurobarómetro 75.2 . 
medioambientales los medios de comunicación españoles y, en concreto, la televisión, que es señalada por los encuestados como su principal fuente de información sobre estos temas.

El planteamiento metodológico adoptado es básicamente cualitativo, tanto en la selección de la muestra como en su análisis. De esta forma, el interés no se sitúa tanto en el estudio de la presencia cuantitativa de este tipo de noticias, como del contenido de las mismas. Así, el objetivo principal es analizar las características del discurso informativo en televisión sobre los riesgos y problemas medioambientales y, en concreto, en torno a las siguientes dimensiones: referencias expresas a riesgos medioambientales, consecuencias, causas y soluciones.

\section{Medios de comunicación y riesgo medioambiental}

Según la teoría de la agenda-setting, aquellos asuntos que reciben una mayor atención por parte de los medios de comunicación son, frecuentemente, reconocidos como importantes por el público y pueden convertirse también en prioridades en el ámbito político. Es decir, los medios influyen en la importancia relativa que se les otorga a los distintos temas en la agenda pública y en la agenda política (McComBs, 2005). Estudios desarrollados desde estos planteamientos también han concluido que los medios de comunicación, y especialmente los espacios informativos, pueden ejercer un papel fundamental a la hora de establecer la agenda pública en el caso concreto de los temas medioambientales (HANSEN, 2011: 18).

Estas investigaciones, que aplican una metodología cuantitativa, califican de inestable la cobertura mediática de los problemas medioambientales, con subidas y bajadas (CORBETT y DurfeE, 2004: 133), dependiendo de diferentes factores como puede ser la existencia de acontecimientos sobre los que informar (BOYKOFF y MANSFIELD, 2008: 3) o el contexto económico. En concreto, la situación económica ejerce una influencia destacada de forma que en los períodos de crisis tiende a reducirse la presencia mediática del medio ambiente (HANSEN, 2011: 14). Ahora bien, en términos generales, el medio ambiente no parece ser una prioridad en la programación televisiva y, específicamente, en los espacios informativos (CARABAZA et al., 2007; McCoMAS et al., 2001; LEÓN, 2007). De hecho, puede destacarse este rasgo, la ausencia de referencias, como una de las características del discurso (o no discurso) medioambiental de los medios de comunicación (HowARD-WiLliams, 2011: 39).

Los riesgos medioambientales carecen de las características que suelen convertir a un hecho en noticiable. Los espacios informativos (especialmente en televisión) prefieren eventos concretos, recientes y novedosos; frente a procesos de lento y largo desarrollo, plagados de incertidumbres y no siempre asociables con acontecimientos o imágenes mediáticamente efectivas (HowARD-WILliams, 2011: 29; REVKIN, 2007: 147). De esta forma, el riesgo medioambiental accede a los telediarios cuando se relaciona con un evento concreto, ya sea un específico desastre medioambiental, conflictos políticos o actividades de famosos (MILLER y RIECHERT, 2000: 48); mientras que desaparece del espacio informativo si no hay nada nuevo sobre lo que informar (MAJOR y ATwOOD, 2004: 170). Por ello, suele afirmarse que las noticias medioambientales son mayoritariamente event centered (AllaN, 2002: 107). 
Uno de los enfoques más productivos en el análisis del tratamiento mediático de los temas medioambientales es la creciente aplicación del concepto de framing o encuadre (HANSEN, 2011: 15). Tal y como plantea McCombs (2005), cuando los medios hablan sobre un tema destacan determinadas características mientras que ignoran otras. De esta forma, no sólo construyen una agenda de temas sino también una agenda de atributos para cada uno de esos temas. ENTMAN (2004: 5) define el proceso de encuadre como "selecting and highlighting some facets of events or issues, and making connections among them so as to promote a particular interpretation, evaluation, and/or solution". Los frames seleccionan causas, culpables y soluciones, ejerciendo un papel fundamental a la hora de dirigir la atención del público en la definición de riesgos (HANSEN, 2011: 15; GORDON et al., 2010: 145).

En líneas generales, las investigaciones desarrolladas en torno a la presencia en los medios de la temática ambiental suelen coincidir en destacar un tratamiento simplista, centrado en la presentación de "eventos ambientales sin una contextualización que explique la problemática ambiental desde lo político, lo económico, lo social" (CARABAZA, 2006). Así, aunque proteger el medio ambiente se tiende a mostrar como algo positivo e incluso necesario (HowARD-WILLIAMS, 2011: 38), los medios no suelen explicar los procesos implicados, su relevancia y relación con otras esferas sociales, las principales causas y culpables, las relaciones de poder en las que se enmarcan o las soluciones existentes y sus posibilidades de aplicación (KNIGHT, 2010:4; JöNSSON, 2011: 129). En definitiva, según Howard-WiLliams (2011: 39), los medios no parecen estar aportando "the resources needed for audiences to properly understand the issues involved and take meaningful action".

A partir de estas investigaciones, nuestro objetivo es analizar el discurso en torno a los riesgos medioambientales en los espacios informativos españoles, considerando las referencias directas a problemas medioambientales, consecuencias, causas y soluciones. Para el caso español, existen estudios previos en este campo (ver LEÓN, 2007), si bien la bibliografía existente es todavía reducida. En gran medida, las investigaciones se han centrado en la consideración de temáticas o acontecimientos medioambientales concretos (FERREIRA et al., 2006; VICENTE-MARIÑo, 2010; ElÍAs, 2006; OdRIOZOla, 2010), así como desde una perspectiva educativa (Vílchez, 2009; CALERo et al., 2006) y del periodismo ambiental (FERNÁNDEZ PARRAT, 2006; FERNÁNDEZ REYES, 2004).

\section{Planteamiento metodológico}

Para llevar a cabo esta investigación, se ha tomado una muestra de telediarios de las tres cadenas de televisión en abierto con mayores índices de audiencia a nivel nacional: TVE1, Antena3 y Tele5. Incluimos, así, la diversidad que supone contar con una cadena pública y dos privadas. De estas cadenas, hemos seleccionado un total de 84 programas informativos, todos emitidos entre el 29 de octubre de 2007 y el 3 de febrero de 2008. Con la selección de este período de tiempo pretendíamos cubrir varios objetivos. Por un lado, incluir los espacios informativos ligados al final de un año, y que podrían incorporar evaluaciones de lo acontecido en los meses anteriores; por otro, ampliar temporalmente la muestra de forma que pudiéramos evitar los sesgos ligados a hechos de especial relevancia. En este sentido, en el período analizado no tiene lugar ningún 
acontecimiento de gran envergadura que afectara a España y que pudiera implicar la configuración de un período especial para esta temática. Igualmente, la muestra analizada se sitúa en un momento previo al pleno estallido de la actual crisis económica. Dada la influencia que el contexto económico suele tener sobre la presencia mediática de los temas medioambientales (HANSEN, 2011: 14), consideramos de especial interés el hecho de contar con una muestra procedente de un periodo de cierta normalidad, ya que nuestro objetivo no es analizar la presencia cuantitativa del medio ambiente ni su evolución, sino las características del discurso mediático en torno a este tema.

De esta forma, el período analizado abarca 14 semanas, para cada una de las cuales se grabaron 6 telediarios: uno entre semana y otro el fin de semana de cada una de las cadenas. Con estos criterios, se dejó libertad a las personas encargadas de la grabación a la hora de seleccionar el día concreto y la edición (mediodía o noche), advirtiendo de la necesidad de cierta alternancia en relación al momento de emisión. Con ello, nuestro objetivo era alcanzar la mayor diversidad posible dentro de la muestra, así como el mismo número de telediarios para cada cadena.

Los 84 informativos seleccionados fueron grabados y visionados, con el fin de localizar aquellas noticias que formarían parte de la muestra definitiva. En concreto, hemos analizado todas aquellas piezas informativas que, o bien hacían referencia directamente a problemas medioambientales (contaminación, cambio climático, vertidos, etc.) o, en cualquier otro sentido, al medio ambiente y la naturaleza, tal y como han hecho otros investigadores (MAJOR y ATWOOK, 2004; NIK, 2007; GERBER et al., 2011; LEÓN, 2007). Entre otras cuestiones, esta estrategia permite analizar tanto la presencia como la ausencia de referencias a problemas medioambientales en noticias sobre el medio ambiente, considerando ambas posibilidades igualmente relevantes.

Siguiendo estos criterios, construimos una muestra final compuesta por un total de 138 noticias. Estas noticias fueron trascritas en su totalidad (incluidos titulares y resúmenes) a la vez que se recogió información referida a: cadena de emisión y edición (mediodía o noche), extensión, descripción de imágenes, presencia en titulares y conexión con periodista en el lugar de la noticia. Finalmente, se aplicaron técnicas cualitativas de análisis; de manera que la información ha sido ordenada, codificada y clasificada buscando discursos comunes y divergentes en torno a cuatro grandes dimensiones: referencia a riesgos medioambientales, causas, consecuencias y soluciones. El proceso de codificación se llevó a cabo con el soporte del programa Atlas-ti, que facilitó la aplicación de los principios de la grounded theory (CHARMAZ, 2006) en el análisis de las características del discurso en torno al medio ambiente.

\section{Resultados}

En coherencia con los resultados obtenidos por otros investigadores (NIK, 2007: 66; WILSON, 2000: 207; MiLlER y RIECHERT, 2000: 48), prácticamente todas las noticias que componen la muestra están directamente relacionadas con un evento. Es decir, un hecho ha tenido lugar, es recogido por las noticias y justifica la presencia del medio ambiente en el espacio informativo. Dicho de otra forma, los temas medioambientales parecen no tener espacio en los telediarios sin que haya sucedido un evento relacionado sobre el que informar. Otra cuestión es que estos eventos pueden ser, o no, 
enmarcados en una temática más amplia, relacionados con otros fenómenos y, en definitiva, explicados en mayor o menor grado.

La estrecha identificación entre acontecimientos y noticias permite clasificar a éstas últimas, según el evento tratado, en cinco categorías, que pueden agruparse de acuerdo al protagonismo que otorgan a los problemas medioambientales (ver tabla 1). Cuando hablamos de la presencia de problemas medioambientales nos referimos a la existencia de referencias explícitas a situaciones de degradación medioambiental ocasionadas, fundamentalmente, por la acción humana. Así, se incluye bajo la noción de problema medioambiental desde incendios, vertidos o animales amenazados; hasta el cambio climático o la contaminación. Estos problemas pueden protagonizar las noticias, configurarse en tema secundario o simplemente estar ausentes en piezas informativas que tratan otras temáticas relacionadas con el medio ambiente y la naturaleza.

Tabla 1. Tipología de noticias

\begin{tabular}{|c|l|}
\hline & \multicolumn{1}{|c|}{ Eventos } \\
\hline \multirow{2}{*}{$\begin{array}{c}\text { Los problemas medioambientales como tema } \\
\text { principal }\end{array}$} & Actos, decisiones, declaraciones, medidas \\
\cline { 2 - 2 } & Desastres medioambientales \\
\hline \multirow{2}{*}{$\begin{array}{c}\text { Los problemas medioambientales no son la te- } \\
\text { mática principal o ni siquiera son nombrados }\end{array}$} & Fenómenos meteorológicos \\
\cline { 2 - 2 } & Muertes o accidentes con causa en la naturaleza \\
\cline { 2 - 2 } & Acontecimientos protagonizados por animales \\
\hline
\end{tabular}

Respecto a las noticias que como tema central tratan problemas medioambientales, y aunque cuantificar no es nuestro objetivo, podemos destacar su relativamente baja presencia. Suponen el $30 \%$ de la muestra, con un especial protagonismo de TVE1 (que emite algo más de la mitad de estas noticias). Dentro de este grupo, se diferencian dos categorías: por un lado, aquellas que hacen referencia directa a medidas, decisiones, declaraciones o actos; por otro, las que informan sobre desastres medioambientales.

\subsection{Medidas, decisiones, declaraciones 0 actos}

Noticias que informan sobre un acontecimiento concreto (ya sea la comparecencia pública de alguien, la presentación de un informe o un acto protagonizado por algún movimiento social) y no tanto sobre la problemática en la que se enmarca. Así, por ejemplo, puede ser noticia que se haya hablado sobre un problema medioambiental, sobre todo si ha tenido lugar en España, y no tanto qué se ha dicho sobre tal problema. En este sentido, los acontecimientos narrados consisten, mayoritariamente, en eventos diseñados para ser recogidos por los medios: ruedas y notas de prensa, presentaciones, declaraciones, actos de denuncia por parte de los movimientos sociales, etc. Las referencias directas al "cambio climático" tienen un especial protagonismo, aunque también se emplean otros términos como "calentamiento global", "especies protegidas" o "contaminación", que permiten clasificar la noticia bajo una temática concreta sin necesidad de ampliar la información al respecto. En la tabla 2 se resume la diversidad de noticias que podemos encontrar bajo esta categoría junto a sus principales características y algunos ejemplos. 
Tabla 2. Noticias sobre medidas, declaraciones o actos

\begin{tabular}{|c|c|}
\hline Eventos & Características y ejemplos \\
\hline $\begin{array}{l}\text { Medidas, } \\
\text { decisiones, planes }\end{array}$ & $\begin{array}{l}\text { Noticias breves sobre: medidas concretas de efectos limitados o referencias generales a } \\
\text { propuestas de acción de más amplio alcance. } \\
\text { "El presidente Zapatero [...] ha inaugurado dos nuevas instalaciones de energía solar en } \\
\text { el complejo de la presidencia del gobierno" (P50-27/11/2007 - Antena3) } \\
\text { "El Ministerio de Defensa ha presentado hoy esta campaña en imágenes para que el } \\
\text { Ejército se comprometa más con el Medio Ambiente" (P88-10/11/2007 - TVE1). } \\
\text { "Para evitar imágenes como ésta de contaminación en Madrid, España tendrá que } \\
\text { reducir en el } 2020 \text { un } 10 \% \text { la emisión de gases efecto invernadero y producir un } 20 \% \\
\text { de energías renovables, es la propuesta de Bruselas para luchar contra el cambio } \\
\text { climático" (P38 - 23/01/2008 - Tele5). }\end{array}$ \\
\hline $\begin{array}{l}\text { Declaraciones, } \\
\text { reuniones, } \\
\text { encuentros }\end{array}$ & $\begin{array}{l}\text { Eventos protagonizados por personajes públicos, representantes institucionales, } \\
\text { expertos, etc. no directamente relacionados con la toma de decisiones en este campo. } \\
\text { "En su tradicional mensaje de Navidad, Benedicto XVI [...] ha alertado de los } \\
\text { preocupantes desequilibrios ambientales" (P1-25/12/2007- Antena3). } \\
\text { "Desde Valencia, Ban Ki-moon, ha dicho que aún estamos a tiempo de evitar el } \\
\text { desastre que puede provocar el cambio climático" (P78-17/11/2007-Tele5). } \\
\text { "De cambio climático se habla hoy en Indonesia" (P18-08/12/2007-Tele5). }\end{array}$ \\
\hline $\begin{array}{l}\text { Actos y denuncias } \\
\text { de movimientos } \\
\text { sociales }\end{array}$ & $\begin{array}{l}\text { La noticia es que ha tenido lugar un concreto acto o denuncia, y no tanto su contenido. } \\
\text { Apenas se muestran las argumentaciones de las ONGs ni hablan sus portavoces. } \\
\text { "Hoy se celebra el día internacional de los derechos de los animales y contamos con una } \\
\text { famosa más en la lista de los muchos conocidos que han puesto rostro y cuerpo a las } \\
\text { campañas que reivindican sus derechos" (P16 - 08/12/2007 - Tele5). } \\
\text { "50 personas se han desnudado frente a la catedral de Barcelona, pintadas de rojo, } \\
\text { quieren simbolizar el sufrimiento de los animales a los que se les arranca la piel para } \\
\text { fabricar prendas de vestir" (P39- 27/01/2008 - Tele5). } \\
\text { "Miembros de la tripulación del buque Esperanza perteneciente a Greenpeace aseguran } \\
\text { haberse enfrentado a un ballenero japonés" (P63 - 12/01/2008 - Antena3). }\end{array}$ \\
\hline
\end{tabular}

\subsection{Desastres medioambientales}

Noticias que suelen consistir en una mínima descripción de un específico desastre, ya sea un incendio, un episodio de contaminación (P135 - 29/01/2008 - TVE1: "La contaminación aumentará otra vez mañana en Madrid") y, sobre todo, vertidos de petróleo en el mar. Muestran desastres concretos y relativamente visibles, que pueden ir acompañados de imágenes de considerable poder visual. Suelen ser breves, sin apenas explicaciones en torno al alcance de los desastres o procesos implicados. Recogen perfectamente estas características las noticias sobre desastres medioambientales fuera de España, especialmente vertidos en el mar:

"Como ven, ya está tiñendo la costa de negro la costa el mayor desastre medioambiental que ha asolado Corea del sur. Decenas de voluntarios intentan limpiar las playas, mientras el vertido del petróleo camina impasible hacia la costa. La catástrofe está arrasando la zona más turística del país y amenaza el único parque natural que hay en corea del sur" (P19 08/12/2007- Tele 5).

Si bien estas características son las dominantes, y aunque sería necesaria una muestra más amplia para establecer claras diferencias entre cadenas, no podemos dejar de destacar las peculiaridades de TVE1 en el tratamiento de estas noticias. Es decir, la ca- 
dena pública, no sólo concede una mayor atención a los eventos sobre problemas y riesgos medioambientales, sino que, además, difiere en su tratamiento en comparación con las cadenas privadas. Así, aunque también podamos calificar de event-centered las noticias emitidas; en algunas ocasiones estos acontecimientos parecen tomarse como excusa para informar sobre la temática correspondiente. Es decir, que hayan tenido lugar unas declaraciones o la presentación de un informe permiten hablar, directamente, del correspondiente riesgo medioambiental. De esta forma, TVE1 tiende a contextualizar en mayor medida los eventos, incluso aportando información y fuentes adicionales. Las siguientes noticias son ejemplos de este tratamiento diferenciado por parte de la cadena pública:

- P131 - 23/01/2008: Además de informar sobre la existencia de una propuesta de la Comisión Europea para frenar el cambio climático, se resumen algunos de sus contenidos.

- P102 - 27/11/2007: Tras señalar la instalación de placas solares en la Moncloa, se informa sobre el cambio climático, sus causas y efectos. De este acontecimiento también contamos en la muestra con lo emitido por las otras cadenas, que se limitan a tratar la instalación de las placas y las declaraciones del Presidente del Gobierno.

- P95 - 17/11/2007: Declaraciones del secretario general de la ONU, en Valencia, sobre la necesidad de frenar el cambio climático. A diferencia de las cadenas privadas, TVE1 amplía la noticia con fuentes adicionales e información extraída del propio informe que estaba presentando Ban Ki-moon.

- P130 - 15/01/2008: Noticia relativamente breve pero que destaca los principales resultados de un estudio elaborado por la Sociedad Española de Ornitología sobre el efecto del cambio climático en las aves. Este tipo de contenidos no aparece en las cadenas privadas.

Ahora bien, en la mayor parte de la muestra, en concreto, en un $70 \%$, los problemas medioambientales o no son la temática principal o ni siquiera son mencionados. Se trata de noticias que, de nuevo, pueden ser clasificadas de acuerdo al acontecimiento que las protagoniza y que, por tanto, informan sobre: fenómenos meteorológicos, daños o accidentes con causa en la naturaleza y noticias sobre animales. En la tabla 3 se recogen las principales características de todo este conjunto de contenidos.

Tabla 3. Características de las noticias en las que los problemas medioambientales no son la temática principal

\begin{tabular}{|l|l|l|l|}
\hline Categoría & \multicolumn{2}{|c|}{ Principales características } & Relación con problemas ambientales \\
\hline & $\begin{array}{l}\text { Narración de un fenómeno } \\
\text { concreto, ya sea una tormenta o }\end{array}$ & Sin relación explícita. Sólo TVE1 establece \\
una subida puntual de la tal relación en dos ocasiones, aunque de \\
temperatura. Uso generalizado de forma indirecta.
\end{tabular}




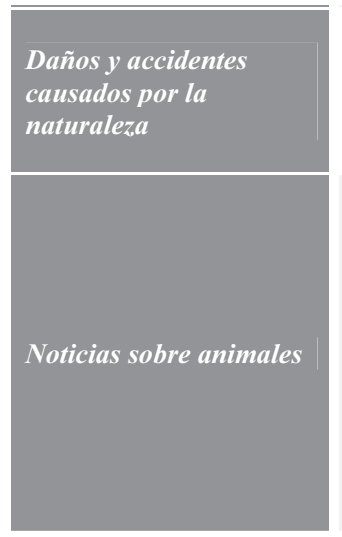

Especial protagonismo del mar y la montaña. Representan la lucha entre los seres humanos (o mejor dicho, los hombres) y la naturaleza.

Noticias breves, que giran en torno a: curiosidades animales, concretos animales peligrosos y referencias al sector de la pesca o la ganadería.
Sin relación ni referencias explícitas a problemas o riesgos medioambientales.

Escasa relación. Las especies nombradas pueden estar en peligro de extinción, pero la noticia se centra en curiosidades o en experiencias de especímenes concretos. Los animales que protagonizan la noticia pueden llegar a morir pero no se sitúan las causas en problemas medioambientales. La información sobre pesca aparece sólo en TVE1, donde se hace referencia a agresiones medioambientales, aunque el tema central son las dificultades para el sector pesquero.

Las noticias más numerosas son las que narran fenómenos meteorológicos, que, de hecho, representan en torno al $50 \%$ del total de la muestra. Se trata de un contenido atractivo para los espacios informativos, que permite un lenguaje informal, con periodistas en el lugar de la noticia e imágenes de relativo poder visual. Muchos de estos fenómenos afectan a un espacio geográfico cercano al lector y pueden incorporar contenido emocional a partir de la narración de experiencias particulares. Cuando los fenómenos meteorológicos afectan a otros países diferentes a España, las noticias suelen ser breves, pero con un elevado contenido dramático a través del lenguaje, verbal y visual, empleado.

La posibilidad de que los fenómenos meteorológicos narrados (ya sean ciclones, tormentas o periodos de sequía) pudieran derivarse de problemas medioambientales (como el cambio climático) no se expresa. La excepción es TVE1 que, en dos ocasiones, tras sendas noticias sobre el cambio climático, introduce de la siguiente manera información referida a fenómenos meteorológicos:

"Y el medio ambiente nos lleva a hablar del tiempo, de un mes de enero especialmente caluroso" (P132 - 23/01/2008).

"En Bangladesh, uno de los países más vulnerables a este incontestable cambio climático, hoy cuentan los muertos por el ciclón Sidr" (P96 - 17/11/2007).

Esta ausencia de relación directa parecería responder a la postura dominante en el ámbito científico que niega la posibilidad de asociar un fenómeno meteorológico concreto al cambio climático (UNGAR, 1999: 142). Sin embargo, los informativos podrían estar induciendo a pensar en la existencia de cierta relación sin directamente hacerla explícita y ello a través de dos elementos que caracterizan, en términos generales, las noticias sobre fenómenos meteorológicos: la intensidad y novedad de los acontecimientos. Dicho de otra forma, la manera en que son narrados los eventos meteorológicos puede transmitir la idea de que cada vez son más frecuentes los fenómenos raros o extremos y que estos aumentan en magnitud e impacto.

En este sentido, las noticias suelen destacar el carácter novedoso, inusual o extraordinario de los eventos meteorológicos. Rasgo que, en otras cuestiones, estaría jus- 
tificando su inclusión en el espacio informativo (BEDNAREK, 2006: 17) y que puede ser expresado, directamente, a través de los periodistas o mediante las declaraciones de ciudadanos, tal y como se muestra en los siguientes ejemplos:

"Estar en diciembre con temperatura incluso por encima de los 20 grados es algo absolutamente inusual" (P21 - 08/12/2007 - Tele 5).

"Pesimismo y preocupación ante uno de los inviernos más secos de hace décadas" (P72 - 02/02/2008 - A3).

"El otoño menos lluvioso en medio siglo está obligando a restringir el agua en algunas aldeas" (P86 - 10/11/2007 - TVE1).

"Yo tengo casi 80 años y no he visto nunca una cosa de estas" (P74 - 21/11/2007 Tele5).

Por otra parte, es común el uso de cifras, palabras e imágenes que transmiten la importancia e intensidad de los fenómenos que se están describiendo, incluso cuando estos no son especialmente violentos. Así, es usual emplear términos como: intensas, enormes, fuerte, tromba, aguas embravecidas, ola de frío, alertas, infierno, gélido, tremendo, etc. Aunque también se emplean en las noticias de ámbito nacional, destaca el uso de estos términos en las noticias de casos internacionales:

"En China, la situación es mucho peor, se sufre el invierno más duro de los últimos 50 años. Hay miedo entre la población, han muerto ya decenas de personas y este fin de semana se esperan más nevadas" (P71 - 02/02/2008 - A3).

"El violento huracán ha dejado 1800 muertos. 48 horas después de su paso, se siguen buscando cadáveres en las zonas devastadas en el que es ya el peor huracán que ha azotado el país en 100 años" (P77 - 17/11/2007 - Tele5).

Ahora bien, de nuevo, podemos hablar de diferencias, en el tratamiento de estas noticias, entre las cadenas privadas y TVE1, donde el uso de adjetivos y términos superlativos no es tan dominante. Es más, en esta cadena, encontramos contenidos en los que se muestra, a un mismo tiempo, tanto la intensidad de los eventos narrados como su relativa normalidad; tratamiento, en todo caso, ausente en las cadenas privadas. A modo de ejemplo:

"En Cataluña estaban en alerta por las previsiones de nevadas aunque finalmente parece que ha caído menos nieve de lo que se esperaba y se ha desactivado el plan especial de emergencia. En la provincia de Tarragona está Judith Huerta y parece, sin embargo, por lo que vemos en la imagen, que el ambiente es casi de postal navideña" (P110 - 18/12/2007 - TVE1).

\subsection{Consecuencias, causas y soluciones}

En términos generales, las explicaciones en torno a consecuencias, causas y soluciones son relativamente reducidas. Respecto a las consecuencias de los problemas medioambientales, las noticias tienden a indicar, en mayor medida, qué es o puede ser afectado, que a detallar en qué consisten tales daños o consecuencias. De esta forma, pueden señalar que los problemas medioambientales afectan o afectarán a determinados países, ciudades, a España, los animales, a todos, las costas, etc., incluso pueden llegar a destacar la importancia de tales efectos (comparables a los de "una ter- 
rorífica película de ciencia ficción" - P78 17/11/2007 Tele5), pero sin llegar a concretar en qué consisten. Las consecuencias parecen sobreentenderse, sin necesidad de incluir información adicional, simplemente al hacer referencia a la problemática, ya sea el cambio climático, vertidos de fuel en el mar o la contaminación.

Por otra parte, las explicaciones en torno a causas y, especialmente, culpables, son también limitadas. En todo caso, es posible encontrar referencias generales sobre causas, pero realmente inusual localizar contenidos en torno a culpables o responsables con cierto grado de concreción. En la tabla 4 se ha resumido el conjunto de referencias relacionadas con causas y culpables que aparecen en la muestra; siendo las dos primeras categorías las más comunes.

Tabla 4. Causas y culpables de los problemas medioambientales

\begin{tabular}{|c|c|}
\hline Causas y/o culpables & Explicación \\
\hline Sin referencias & $\begin{array}{l}\text { Fenómenos que simplemente ocurren, son accidentes, tragedias, } \\
\text { desequilibrios; sin referencia alguna a causas ni culpables. Incluso, tal y como } \\
\text { reproduce Tele5 (P78 - 17/11/2007), "los culpables no son importantes". }\end{array}$ \\
\hline Procesos globales & $\begin{array}{l}\text { Sitúan la causa en el consumo energético, la emisión de gases, los modos de } \\
\text { producción y consumo, el modelo energético, etc. No se señalan culpables u } \\
\text { otras características de estos procesos, como intereses o relaciones de poder. }\end{array}$ \\
\hline Todos nosotros & $\begin{array}{l}\text { Noticias que hacen referencia a un nosotros genérico como causa. Parecen } \\
\text { reflejar lo que, entre todos, le estamos haciendo a nuestro planeta: "En España } \\
\text { emitimos cada año más de } 7 \text { toneladas de CO2 por persona" (P102 - } \\
27 / 11 / 2007 \text { - TVE1). }\end{array}$ \\
\hline Países especificos & $\begin{array}{l}\text { Categoría residual. Noticias que reproducen los desacuerdos en torno a qué } \\
\text { países son los más contaminantes, sobre todo en la dicotomía ricos-pobres. }\end{array}$ \\
\hline Responsables concretos & $\begin{array}{l}\text { Categoría residual. Culpables concretos que son señalados en relación con } \\
\text { eventos específicos, por ejemplo, turistas "desconsiderados" que } \\
\text { contaminación un río (P17 - 08/12/2007 - Tele5) o un barco que caza ballenas } \\
\text { (P63-12/01/2008 - A3). }\end{array}$ \\
\hline
\end{tabular}

Finalmente, y siempre hablando en términos generales, tampoco son extensas las referencias a soluciones, si bien aparecen con más frecuencia que los contenidos relativos a causas. Las noticias suelen centrarse más en señalar qué aspectos deben ser cambiados (reducción de emisiones, cambios en el modelo energético, etc.) que en explicar, con cierto grado de detalle, en qué consisten esos cambios y cómo han de realizarse. Ahora bien, a diferencia de lo visto en el análisis de causas y culpables, al hablar de las transformaciones que han de llevarse a cabo, observamos una tendencia a concretar responsabilidades $y$, aunque sea de forma genérica, a hacerlo en los gobiernos o en un "todos nosotros". Es decir, ya no se habla, simplemente, de la necesidad de reducir las emisiones de $\mathrm{CO} 2$, por ejemplo, sino de la necesidad de que los gobiernos o los ciudadanos lo hagan. En la tabla 5 se resume la información que aportan las noticias en referencia a soluciones y actores implicados en las mismas; una vez más, las dos primeras categorías son las más comunes. 
Tabla 5. Soluciones y actores implicados

\begin{tabular}{|c|c|}
\hline $\begin{array}{l}\text { Soluciones } y / 0 \\
\text { actores }\end{array}$ & Explicación \\
\hline Todos nosotros & $\begin{array}{l}\text { Noticias que parecen intentar involucrar a la audiencia, sin concretar las acciones } \\
\text { que deben realizarse más allá de señalar que hemos de cambiar el modelo } \\
\text { energético, reducir las emisiones, producir más energías renovables, etc. Se } \\
\text { encuadran en esta categoría noticias que destacan el papel del voluntariado, la } \\
\text { conciencia ciudadana o que muestran a los seres humanos cuidando y protegiendo } \\
\text { animales o entornos naturales. }\end{array}$ \\
\hline Gobiernos & $\begin{array}{l}\text { Noticias que tratan, o la aplicación de medidas concretas y de relativo corto alcance } \\
\text { por parte del gobierno español o gobiernos regionales; o llamamientos a los } \\
\text { gobiernos para hacer algo, ya sea desde la Unión Europea, la ONU o movimientos } \\
\text { sociales. La información se orienta más a indicar qué cambiar y no tanto a cómo. }\end{array}$ \\
\hline $\begin{array}{l}\text { Sin referencias a } \\
\text { soluciones }\end{array}$ & $\begin{array}{l}\text { Noticias que se limitan a la mera denuncia o mención del problema medioambiental } \\
\text { al que hacen referencia. }\end{array}$ \\
\hline $\begin{array}{l}\text { Desarrollo } \\
\text { tecnológico y } \\
\text { cientifico }\end{array}$ & $\begin{array}{l}\text { La solución parece situarse en el desarrollo de tecnologías aplicadas a la producción } \\
\text { energética y en avances científicos. Noticias que suelen centrarse en innovaciones } \\
\text { desarrolladas en España o por españoles, destacando la capacidad pionera en este } \\
\text { campo: "Este girasol gigante, un aparato pionero, fabricado con tecnología española, } \\
\text { proporcionará el } 10 \% \text { de la energía que gasta el complejo de la Moncloa" (P14 - } \\
27 / 11 / 2007 \text { - Tele5). }\end{array}$ \\
\hline Ámbito empresarial & $\begin{array}{l}\text { Categoría residual. Encontramos escasas referencias y, en todo caso, meras } \\
\text { menciones. Presencia en las noticias sobre el sector pesquero en TVE1, en las que se } \\
\text { destaca tanto la disposición de las empresas a la hora de buscar soluciones, como la } \\
\text { complejidad de las mismas. }\end{array}$ \\
\hline $\begin{array}{l}\text { Remediar desastres } \\
\text { medioambientales }\end{array}$ & $\begin{array}{l}\text { En referencia a los desastres medioambientales, el discurso predominante es en } \\
\text { torno a remedios y no prevención; es decir, las noticias se centran en las medidas } \\
\text { que se están aplicando una vez el desastre ha tenido lugar. Estos remedios } \\
\text { (tecnológicos o basados en el voluntariado o en la acción de los gobiernos) suelen } \\
\text { mostrarse limitados en sus posibilidades. }\end{array}$ \\
\hline
\end{tabular}

En definitiva, los contenidos referidos a soluciones, consecuencias y, sobre todo, causas, son limitados. Las explicaciones son breves, simples; sin indicar culpables o hacer referencias explícitas a los procesos sociales que generan los diferentes problemas medioambientales. Puede deducirse de estas noticias, que el riesgo medioambiental es real y grave, aunque no se detallen sus consecuencias. No importa tanto cuáles sean las causas, pero sí parece haber soluciones. Eso sí, se indica más quién debe actuar (los gobiernos y todos los ciudadanos) que, con cierto nivel de detalle, cómo han de hacerlo. En todo caso, a pesar de la gravedad del tema, parece destacarse una dimensión positiva en la medida en que está parcialmente en nuestras manos llevar a cabo los cambios necesarios para limitar el deterioro medioambiental.

A pesar de este panorama general, una vez más, debemos destacar la existencia de importantes diferencias entre los contenidos emitidos por TVE1 y por las cadenas privadas. Aunque, en líneas generales, los resultados expuestos anteriormente también son aplicables a la cadena pública, ésta tiende a emitir más información, detalles y fuentes, sobre todo en referencia a consecuencias y soluciones. Así, por ejemplo, en P130 (15/01/2008) se resume un estudio sobre los efectos del cambio climático en las aves; en P95 (17/11/2007), además de señalar que Ban Ki-moon ha estado en Valencia presentando un informe (como prácticamente se limitan a hacer las cadenas pri- 
vadas), se amplía la información con contenidos del citado informe; o P89 (13/11/2007), donde se tratan los efectos a largo plazo del vertido al mar de fuel del Prestige, cinco años después de que sucediera. Todo ello, contenidos ausentes de las cadenas privadas.

\section{Conclusiones}

Considerando el conjunto de noticias analizadas, la naturaleza puede aparecer como amenazante y peligrosa, dañada y necesitada de protección o, simplemente, como bella o curiosa, en coherencia con lo visto por otros autores (NIK, 2007: 64-65; HowARD-WILLIAMS, 2011: 40). La naturaleza como amenaza es la forma dominante en las noticias no protagonizadas por problemas medioambientales; mientras que, cuando las noticias se centran en estos problemas, aunque la naturaleza suele aparecer como dañada y necesitada de protección, predomina, directamente, su no presencia. Es decir, son noticias sobre contaminación, cambio climático o incluso vertidos pero no sobre el medio natural.

En todo caso, de acuerdo a nuestra muestra, el riesgo medioambiental existe y sus efectos pueden calificarse de graves, aunque no aparezcan detallados. En este sentido, a diferencia de lo observado por otros autores que denuncian una cierta ambivalencia mediática a la hora de hablar de riesgos medioambientales como, por ejemplo, el cambio climático (BOYKOFF y MANSFIELD, 2008: 4); en las noticias analizadas no encontramos voces contrarias o que pongan en duda la existencia de tales riesgos, ni la responsabilidad humana en su generación.

Respecto a posibles causas, se observa una ausencia generalizada de referencias que muestren, con cierto grado de detalle, responsables y procesos sociales implicados en la generación de problemas medioambientales. Esta presencia limitada de contenidos referidos a causas es coherente con los resultados obtenidos por otros investigadores (GERBER et al., 2011: 25), que destacan el carácter no polémico de los espacios informativos. Por su parte, en materia de soluciones, las referencias siguen siendo vagas, aunque más abundantes, y fundamentalmente centradas en indicar los factores que han de modificarse (modelo energético, emisión de gases, consumo, etc.) y los responsables de tales cambios (gobiernos y ciudadanos). Este encuadre parece dotar de una dimensión positiva a las noticias, puesto que se da a entender que existen soluciones (aunque no se detalle cómo aplicarlas), en las que han de implicarse los gobiernos pero en las que también juega un papel determinante la acción individual (HANSEN, 2011: 16).

Sin embargo, algunos autores dudan de los efectos movilizadores de este encuadre que, por un lado, puede suponer una despolitización de los riesgos medioambientales al incidir en el protagonismo de los individuos (Howard-WiLliams, 2011: 40) y, por otro, implica informar sobre unos riesgos, que parecen graves, pero sobre los que se ofrece escasa información en referencia a causas, consecuencias e, incluso, soluciones (Good, 2009).

Las noticias analizadas se pueden calificar, en su mayoría, como event centered, tal y como concluyen otros investigadores (MILLER Y RIECHERT, 2000: 48; WILSON, 2000: 207; MAJOR y ATWOOD, 2004: 170). En definitiva, los riesgos medioambientales pare- 
cen incompatibles con el formato televisivo de los informativos; en los que encuentran cabida a través de eventos concretos (NIK, 2007: 66). Los telediarios muestran sus preferencias por acontecimientos, novedades, certezas, contenidos emocionales y dramáticos, presencia de imágenes, etc. Características acordes con el doble objetivo de informar y entretener, pero no tanto con una transmisión mínimamente detallada de la problemática medioambiental. Ahora bien, aún compartiendo muchos de estos rasgos, la cadena pública TVE1 representa una forma diferente de hablar sobre el medio ambiente. Así, tiende a ofrecer una información más amplia, datos y una mayor diversidad de fuentes; todo ello con niveles de audiencia comparables y, en ocasiones, superiores a los de las dos cadenas privadas ${ }^{3}$. Es decir, la presencia de un mayor componente informativo no parece ser incompatible con el hecho de alcanzar elevados niveles de audiencia.

En todo caso, los contenidos que se emiten están directamente influidos por las fuentes empleadas; siendo éstas un elemento fundamental del proceso de encuadre de las distintas temáticas (JÖNSSON, 2011: 128). Aunque nuestro objetivo no es cuantificar, sí podemos hablar de la presencia dominante de fuentes institucionales en la muestra de noticias, en coherencia con lo observado por otros investigadores (NIK, 2007: 80; CORBERT, 1998: 225). Los expertos sólo aparecen en noticias emitidas por TVE1, que también se hace eco, en mayor medida, de las argumentaciones de los movimientos sociales. En el caso de las cadenas privadas, aunque pueden informar sobre actos organizados por ONGs, no suelen dar la voz a sus portavoces y las noticias toman carácter de anécdota al centrarse fundamentalmente en la dimensión llamativa del acto, tal y como muestran otros estudios (NIK, 2007: 80; FERNÁNDEZ PARRAT, 2006). Por otra parte, los contenidos ofrecidos reproducen, en gran medida, información elaborada por las fuentes para ser recogida por los medios: ruedas y notas de prensa, declaraciones, etc. Así, los periodistas no necesitan analizar los informes o las medidas que se están presentando, sino únicamente el resumen que ofertan sus portavoces (HANSEN, 2011: 11). Con ello, se incrementa el poder de las fuentes en el diseño del contenido que se emite: un resumen con escasas explicaciones. Sin embargo, una vez más, TVE1, aún otorgando relevancia a las fuentes institucionales, muestra otra forma de redactar las noticias, acudiendo a los informes o medidas que están siendo presentados, así como a otras fuentes de información como pueden ser expertos y movimientos sociales.

En definitiva, nuestros resultados coinciden con los obtenidos en investigaciones previas y, en concreto, muestran cierta coherencia con los obtenidos por LEÓN (2007) en su análisis cuantitativo de telediarios españoles. En este estudio se destaca la existencia de información de contexto en las noticias sobre riesgos medioambientales y una calidad relativamente buena de las mismas. En nuestro caso, dado los resultados obtenidos, sólo podríamos coincidir con estas conclusiones respecto a TVE1, que ofrece una información más completa; sin olvidar que es la cadena que en mayor medida emite noticias relacionadas directamente con problemas medioambientales (con-

3 De acuerdo a los datos sobre audiencias que elabora la empresa Kantar Media: www.tnsmedia.es [fecha de consulta: 24 de noviembre de 2011] 
clusiones que parecen coincidir con CARABAZA et al., 2007: 48). Aún así, podemos seguir hablando de ciertas carencias, presentes también en TVE1, sobre todo a la hora de mostrar causas y consecuencias o concretar medidas y soluciones a aplicar o a exigir a los distintos gobiernos.

Por supuesto, sería necesario completar esta investigación con el estudio de las percepciones por parte de la audiencia. Es decir, para poder concluir si los medios movilizan o desmovilizan a la población, necesitamos analizar cómo las audiencias interpretan unos contenidos que parecen indicar que los problemas medioambientales existen, que son importantes, pero cuyas causas no son explicadas y sus soluciones sólo mencionadas, aunque se tienda a responsabilizar de ellas a los gobiernos y los individuos. Tal análisis resulta especialmente relevante cuando los espacios informativos siguen siendo fuente fundamental a la hora de caracterizar y evaluar unos riesgos que suponen una amenaza real, no tan lejana, para la supervivencia de las sociedades humanas.

\section{Referencias bibliográficas}

ALLAN, Stuart (2002): Media, Risk and Science. Buckingham, Open University Press BOYKOFF, Maxwell T. y MANSFIELD, Maria (2008): “'Ye Olde Hot Aire': reporting on human contributions to climate change in the UK tabloid press". Environmental Research Letters, vol. 3, $\mathrm{n}^{\circ}$ 2: http://iopscience.iop.org/1748-9326 /3/2/024002. [fecha de consulta: 21 de noviembre de 2011]

CALERO, Maria et al. (2006): "La atención de la prensa a la situación de emergencia planetaria". Didáctica de las Ciencias Experimentales y Sociales, $\mathrm{n}^{\circ} 20$. Valencia, Universidad de Valencia, pp. 69-88.

CARABAZA, Julieta (2006): "Apuntes para comprender la cultura ambiental desde la comunicación”. Global Media Journal México, vol. 3, nº 6: http://gmje.mty .itesm.mx/carabaza.htm [fecha de consulta: 21 de noviembre de 2011]

CARABAZA, Julieta et al. (2007): "Cobertura del medio ambiente en la televisión mexicana". Comunicación y Sociedad, $\mathrm{n}^{\circ}$ 7. México, Universidad de Guadalajara, pp. 45-76.

CHARMAZ, Kathy (2006): Constructing Grounded Theory: A Practical Guide Through Qualitative Analysis. Thousand Oaks, Sage.

CORBETT, Julia B. y DURFEE, Jessica L. (2004): "Testing Public (Un)Certainty of Science. Media Representations of Global Warming". Science Communication, vol. 26, $\mathrm{n}^{\mathrm{o}}$ 2. Thousand Oaks, Sage, pp. 129-151.

CRITCHER, Chas (ed.) (2006): Critical Readings: Moral Panics and the Media. Maidenhead, Open University Press.

CURRAN, James (2005): Medios de comunicación y poder en una sociedad democrática. Barcelona, Hacer.

ELÍAS, Carlos (2006): "Medio ambiente, manipulación política y control mediático del riesgo. Análisis del caso del hundimiento del petrolero Prestige", Ámbitos, $\mathrm{n}^{\circ}$ 15. Sevilla, Universidad de Sevilla, pp. 171-190. 
ENTMAN, Robert M. (2004): Projections of power: Framing news, public opinion, and U.S.foreign policy. Chicago, University of Chicago Press.

FERNÁNDEZ PARRAT, Sonia (2006): "La información ambiental en los medios de comunicación. Dificultades y retos". Telos. Segunda época, $n^{\circ}$ 68: http://sociedadinformacion.fundacion.telefonica.com/telos/articuloexperiencia.asp@idarticulo\%3D1\&rev\%3D68.htm [fecha de consulta: 21 de noviembre del 2011]

FERNÁNDEZ REYES, Rogelio (2004): "Periodismo ambiental y periodismo sostenible", Ámbitos, no 11-12. Sevilla, Universidad de Sevilla, pp. 311-317.

GERBER, David L.J. et al. (2011): "Animals in the media: New boundaries of risk?". Health, Risk and Society, vol. 13, n ${ }^{\circ}$ 1. Oxford, Taylor and Francis Group, pp. 17-30.

GERBNER, George (1998): "Cultivation analysis: An Overview". Mass Communication and Society, vol. 1, n 3-4. Oxford, Taylor and Francis Group, pp. 175-194.

GOOD, Jennifer E. (2009): "The cultivation, mainstreaming, and cognitive processing of environmentalists watching television". Environmental Communication, vol. 3, $\mathrm{n}^{\mathrm{o}}$ 3. Oxford, Taylor and Francis Group, pp. 279-297.

GORDON, Joye C. et al. (2010): "Global Warming Coverage in the Media: Trends in a Mexico City Newspaper". Science Communication, vol. 32, n 2. Thousand Oaks, Sage, pp. 143-170.

HANSEN, Anders (2011): “Communication, media and environment: Towards reconnecting research on the production, content and social implications of environmental communication". The International Communication Gazette, vol. $73 \mathrm{n}^{\circ}$ 1-2. Thousand Oaks, Sage, pp. 7-25.

HOWARD-WILLIAMS, Rowan (2011): "Consumers, crazies and killer whales: The environment on New Zealand television". The International Communication Gazette, vol. 73, n 1-2. Thousand Oaks, Sage, pp. 27-43.

JÖNSSON, Anna M. (2011): "Framing Environmental Risks in the Baltic Sea: A News Media Analysis". $A M B I O$, vol. 40, nº 2. Berlín, Springer, pp. 121-132.

KNIGHT, Jan E. (2010): "Building and Environmental Agenda: A content and Frame Analysis of News about the Environment in the United States, 1890 to 1960". Tesis doctoral: http://etd.ohiolink.edu/view.cgi?acc_num=ohiou1268687765 [fecha de consulta: 16 de noviembre de 2011).

LEÓN, Bienvenido (2007): "El medio ambiente en las televisiones españolas. Un análisis de contenido de los informativos nacionales", en CONTRERAS, Fernando R. et al.: Cultura verde. Volumen I, Ecología, cultura y comunicación. Sevilla, Junta de Andalucía, pp. 361-373.

MAJOR, Ann M. y ATWOOD, L. Erwin (2004): "Environmental risks in the news: issues, sources, problems and values". Public Understanding of Science, vol. 13, $\mathrm{n}^{\circ}$ 3. Thousand Oaks, Sage, pp. 295-308.

McCOMAS, Katherine A. et al. (2001): "Environmental content in prime-time network TV's non-news entertainment and fictional programs". Society and Natural Resources, vol. 14, n ${ }^{\circ}$. Oxford, Taylor and Francis Group, pp. 533-542. 
McCOMBS, Maxwell (2005): "A look at agenda-setting: Past, present and future". Journalism Studies, vol. 6, n 4. Oxford, Taylor and Francis Group, 543-557.

McQUAIL, Denis (2000): Introducción a la teoría de la comunicación de masas. Barcelona, Paidós.

FERREIRA, Miguel et al. (2006): "La construcción mediática de la realidad: El caso «Prestige»". Nómadas, vol. 14, n 2. Madrid, Universidad Complutense, pp. 28-41.

MILLER, M. Mark y RIECHERT, Bonnie P. (2000): "Interest group strategies and journalistic norms: news media framing of environmental issues", en ALLAN, Stuart et al.: Environmental Risks and the Media. London and New York, Routledge, pp. 45-54.

NIK, Norma (2007): "The representation of environmental news: a comparative study of the Malaysian and New Zealand press", Tesis doctoral: http://ir.canterbury .ac.nz/handle/10092/1904 [fecha de consulta: el 21 de noviembre de 2011]

ODRIOZOLA, Javier (2010): "La crisis del Prestige en la prensa vasca desde una concepción medioambiental". Estudios sobre el Mensaje Periodístico, $\mathrm{n}^{\circ} 16$. Madrid, Universidad Complutense, pp. 331-347.

PIDGEON, Nick et al. (eds., 2003): The Social Amplification of Risk. Cambridge, Cambridge University Press.

REVKIN, Andrew C. (2007): "Climate Change as News: Challenges in Communicating Environmental Science". DiMENTO, Joseph F.C. y DOUGHMAN, Pamela (eds), Climate Change. What It Means for Us, Our Children, and Our Grandchildren. Massachusetts Institute of Technology, pp. 139-160.

TULLOCH, John C. y ZINN, Jens O. (2011): "Editorial: Risk, health and the media". Health, Risk and Society, vol. 13, n ${ }^{\circ}$ 1. Oxford: Taylor and Francis Group, pp. 1-16.

UNGAR, Sheldon (1999): "Is strange weather in the air? A study of U.S. national network news coverage of extreme weather events". Climate Change, vol. 41, $\mathrm{n}^{\mathrm{o}} 2$. Berlin, Springer, pp. 133-150.

VICENTE-MARIÑO, Miguel (2010): “Agendas, encuadres y discursos en los noticiarios televisivos españoles durante la crisis del Prestige". Athenea Digital, no 19. Barcelona: Universidad Autónoma de Barcelona, pp. 249-257.

VILCHES, Lorenzo (1993): La televisión. Los efectos del bien y del mal. Barcelona, Paidós.

VÍLCHEZ, J. Eduardo (2009): "La problemática ambiental en los medios. Propuesta de un protocolo de análisis para su uso como recurso didáctico". Enseñanza de las ciencias, vol. 27, $\mathrm{n}^{\circ}$ 3. Barcelona, Universidad Autónoma de Barcelona, pp. 421-432.

WILSON, Kris M. (2000): "Communicating climate change through the media. Predictions, politics and perceptions of risk", en ALLAN, Stuart et al.: Environmental Risks and the Media. London and New York, Routledge, pp. 201-217. 